\title{
СОВЕРШЕНСТВОВАНИЕ ФОРМ ОРГАНИЗАЦИИ ЛЕСОПОЛЬЗОВАНИЯ В СОВРЕМЕННЫХ УСЛОВИЯХ
}

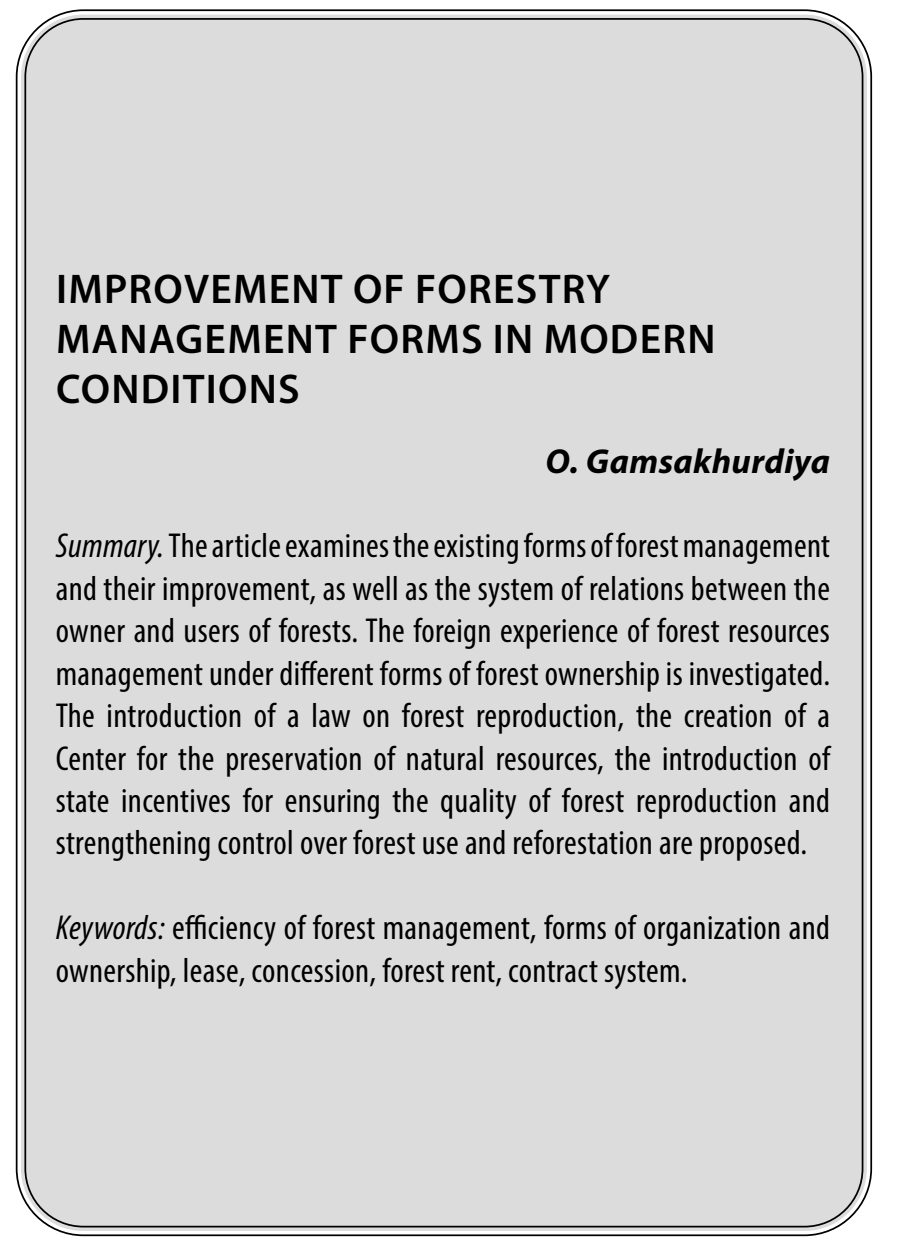

$\boldsymbol{3}$ кономические формы лесопользования, применяемые в настоящее время, представлены в лесном законодательстве в виде: передачи лесов в аренду и договоров купли-продажи лесных насаждений [1].

В России на 1 января 2020 г. на основании 94,4 тыс. договоров в долгосрочное пользование были переданы более 265 млн. га, что составляет 23\% площадей земель лесного фонда, из которых:

- по договорам аренды предоставлены лесные участки площадью 232,5 млн. гектаров,

- в постоянное (бессрочное) пользование предоставлено 3,3 тыс. лесных участков общей площадью 32,5 млн. гектаров,

- в безвозмездное пользование предоставлено 4,3 тыс. лесных участков общей площадью 481 тыс. гектаров.
Гамсахурдия Ольга Владимировна

К.э.н., доцент, Московский государственный технический университет имени Н.Э. Баумана (национальный исследовательский университет) Мытищинский филиал Ole4kamoskow@mail.ru

Аннотация. В статье рассматриваются существующие формы организации лесопользования и их совершенствования, а также система отношений между собственником и пользователями лесов. Исследован зарубежный опыт управления лесными ресурсами при разных формах собственности на леса. Предложено введение закона о воспроизводстве лесов, создание Центра по сохранению природных ресурсов, введение государственного стимулирования за обеспечение качества воспроизводства лесов и усиление контроля за лесопользованием и лесовозобновлением.

Ключевые слова: эффективность лесопользования, формы организации и собственности, аренда, концессия, лесная рента, контрактная система.

На основании договоров купли-продажи лесных насаждений ежегодно заключается примерно 600 тыс. договоров (сроком до 1 года) без предоставления лесных участков. [2].

Арендная форма лесопользования предполагалась в многолесных районах и сегодня законодательно следует запретить ее распространение на малолестные и среднелесистые регионы, где более эффективной будет форма купли-продажи насаждений на корню на основе краткосрочных контрактов. Объем заготовки древесины в динамике за ряд лет свидетельствует о том, что на долю арендаторов приходится $70 \%$ от общего объема.

Анализ арендной формы лесопользования за последнее десятилетие показал, что лесной доход не покрывает расходов на простое воспроизводство древесных ре- 
сурсов и тем более на охрану лесов от пожаров, защиту от вредителей и болезней и борьбу с лесонарушениями, включая нелегальные рубки. Исследуя применения различных форм организации лесопользования, необходимо отметить, что они недостаточно ответственно выполняют требования лесного хозяйства и действующего законодательства в части технологии лесозаготовок, в вопросах платежей за аренду, качества лесовосстановления и др. Средства, получаемые от лесопользования, должны покрывать все расходы на воспроизводство лесов и другие лесные цели. Действующий Лесной кодекс РФ обязал арендаторов осуществлять лесовосстановление и уход за лесами на участках, взятых в аренду.

Договора купли-продажи со сроком действия до одного года и краткосрочные договора аренды со сроком от трех до пяти лет не выгодны арендодателю, так как они не отвечают за состояние лесного фонда и тем более за его восстановление. Получая прибыль, лесопользователи не компенсируют всех затрат по воспроизводству лесных ресурсов и не способствуют повышению эффективности работы лесного сектора. На указанные виды работ приходится около $30 \%$ от общего объема лесозаготовок страны. Это значительные объемы, по которым необходимо законодательно утвердить обязательства пользователей-контракторов (которых сегодня можно считать временщиками в лесу) о возмещении в полном объеме затрат на воспроизводство лесных ресурсов и выполнение других лесохозяйственных работ.

Ни в одном документе не обозначена для контракторов связь технологии заготовки древесины с лесовосстановлением. Одновременно, возникает вопрос: как увязать их средства на воспроизводство лесов со способом лесовосстановления, который им не был обозначен. И как они учитывают при заготовке древесины естественную способность лесов к воспроизводству. Ретроспективный анализ показывает в структуре лесного фонда соотношение сохранения естественного подроста с искусственным лесовосстановлением, как 75:25, то есть лесозаготовитель технологию лесосечных работ должен определять в зависимости от перспективного способа воспроизводства лесных ресурсов, указанном в проекте освоения лесов. Ежегодно в лесах СССР при сплошных рубках сохранялось жизнеспособного подроста более чем на 30\% вырубаемых площадей. Это было обусловлено тем, что сохранение подроста способствует обеспечению вырубок хозяйственно ценными породами, предотвращает смену пород, сокращает сроки выращивания и период восстановления леса, сокращает объемы искусственного лесовосстановления [3].

В современных условиях основными направлениями совершенствования технологии естественного возобновления леса являются:
- согласование проектирования лесных машин с лесоводами;

- повышение квалификации лесных работников;

- совершенствование технологии лесосечных работ (разработка лесосек методом узких лент, трелевка деревьев за вершину и т.п.);

- совершенствование лесного законодательства и соответствующих нормативно-правовых актов.

В настоящее время имеются сторонники замены арендной формы лесопользования на концессии, правовые основы которых изложены в Гражданском кодексе РФ [4]. В действующем Лесном кодексе концессия как форма лесопользования, так и не была предложена, несмотря на многочисленные попытки сторонников концессии обосновать ее преимущество тем, что «концессия - вариант сохранения сособственности» [5].

В современных условиях принятие законодательно концессий как формы организации лесопользования возможно только при наличии крупных инвесторов и при подготовке нормативно-правовых актов для осуществления концессионной деятельности. С этой целью предлагать создать Центр по сохранению природных (в том числе - лесных) ресурсов, который будет заниматься вопросами использования ресурсов и разработкой нормативно-правовой документации.

Лесные специалисты считают, что на улучшение экономической составляющей арендной формы лесопользования может оказать влияние увеличения срока аренды, позволяющее арендаторам получать долгосрочные кредиты для развития производства и взаимодействия лесозаготовительной и лесохозяйственной деятельности.

Организация управления лесными ресурсами зависит от принятого лесного законодательства в стране и системы отношений между государством и лесопользователями, включая арендаторов. Арендные отношения в России формировались на основе изучения зарубежного опыта других стран, например Канады. Кроме того, зарубежный опыт показывает, что организация использования лесов должна быть построена таким образом, чтобы обеспечить эффективность лесовосстановления и компенсировать затраты на него, уход за лесными насаждениями и другие мероприятия в течение всего срока выращивания лесов.

Канада считается крупнейшей лесной державой, где площадь лесов составляет 45\% территории страны при запасах древесины почти в 20 млрд. м³, а 93\% лесных земель принадлежит государству. Лесной сектор страны отличают передовые технологии, организация управления, экономические требования к лесозаготовкам. 
Провинции Канады владеют и управляют природными ресурсами, включая лесные, которые находятся на их территории.

Организация лесопользования и воспроизводства лесов осуществляется на основе лесного законодательства страны. Включающего нормативно-правовые акты: Конституцию страны, Лесной закон, Земельный закон, Закон о восстановлении лесов, Закон об управлении древостоем, Закон о лесных заповедниках, Закон Министерства лесов, Руководство по деятельности в лесу и на пастбищах и др. заключение договоров между государством и лесопользователями при передаче участков лесного фонда в аренду осуществляется на основании перечисленных нормативно-правовых актов. Арендные отношения выступают в виде: соглашения на заготовку древесины, лесной лицензии, лицензии на лесохозяйственное производство, лицензии на покупку леса на корню.

Экономическая организация управления воспроизводством лесов осуществляется посредством лесных платежей и податей. Лесные платежи содержат:

- ежегодные платежи, называемые земельной рентой или платой за владение в соответствии с площадью лесного участка;

- плату в соответствии с объемом вырубленного леса, называемая попенной платой или платежами за древесину на корню.

Платежи за древесину на корню включают:

- минимальные, направляемые в общий доход провинции;

- платежи на лесовосстановление, которые являются обязательными и носят целевой характер и формируются на специальном счете фонда лесовосстановления; при этом их величина зависит от породного состава вырубаемых пород и площадей, и затрат на лесовосстановление в соответствии с планом;

- остаточную стоимость (лесную ренту), которая поступает в доход провинции от лесопользователей, определяется по отдельным видам продукции перерабатывающих производств (целлюлоза, бумага, фанера, пиломатериалы и др.) и исчисляется только при высоких рыночных ценах на продукцию, как разница между рыночной ценой продукции из древесины и затратами на ее производство и реализацию, включая обязательные платежи за пользование лесным фондом, а также нормой прибыли на инвестиции.

Нормативно-правовые акты Канады охватывают всю систему государственного управления лесами. Обязательность целевых платежей на лесовосстановление в зависимости от породного состава повышает ответ- ственность лесопользователей за сохранение лесного фонда и может служить руководством к действию лесопользователям других стран. По примеру Канады в отечественное законодательство целесообразно дополнительно включить Закон о воспроизводстве лесов и Закон об управлении древостоем, которые усилят ответственность лесопользователей за воспроизводство лесных ресурсов.

В США 70\% лесов находится в частном владении, остальные - национальные (государственные) леса или лесные заповедники. Федеральная лесная служба осуществляет только управление национальными лесами и с установленной периодичностью отчитывается перед Конгрессом, Президентом страны и налогоплательщиками за средства, вырученные от реализации древесины. Однако, для выполнения лесозаготовительной деятельности, лесовосстановительных работ с последующим уходом за посадками, борьбы с вредителями и болезнями леса, пожарами привлекает исполнителей на контрактной основе. Таким образом, в лесных отношениях США участвуют государственные органы управления лесами, собственники частных лесов и предприниматели, выполняющие все работы по контрактам. При этом, следует особенно отметить, что финансирование затрат на лесохозяйственную деятельность почти на 70\% обеспечивается из государственного бюджета.

Также не следует забывать о том, что более половины всей площади лесов США занимают так называемые «неиндустриальные» леса, в которых лесохозяйственную и лесозаготовительную деятельность осуществляют частные собственники. Ввиду малого интереса для бизнеса этих лесных участков, объем использования лесных ресурсов в среднем чуть превышает 50\% от возможных объемов, а воспроизводство в этих лесах заключается только в искусственном лесовосстановлении. Несмотря на промышленную непривлекательность эти леса также включаются в общий лесной фонд и рассматриваются в общегосударственной лесной политике страны.

В Финляндии значительную долю составляют частные леса - 58\%, государственные леса - 29\%, леса частных компаний - 8\%, а 5\% лесов находится в других формах собственности.

Ведение лесопользования и воспроизводства лесных ресурсов контролируется государством. В тех случаях, когда после завершения заготовки древесины не осуществляется лесовосстановление, то лесопользование приостанавливается, а средства на лесовозобновление изымаются у лесопользователя. Государство поддерживает стимулированием лесопользователей 
на уход за лесом и обеспечение воспроизводства лесов. Лесовосстановление осуществляется созданием лесных культур, естественным способом и содействием естественному лесовосстановлению. Особое внимание уделяется качеству семенного и посадочного материала, что регулируется Законом о торговле лесокультурным материалом и контролем Центра по инспекции продукции растениеводства.

Последние десятилетия наибольший успех Финляндия достигла в процессе корпоратизации путем консолидации представителей мелкого и среднего бизнеса, фермеров-частных лесовладельцев, множества фирм, организовав на их базе три крупных корпорации UPM, Metsäliitto и StoraEnso, которые на контрактной основе сотрудничают на основе лесных программ. Инновационное развитие получили биоэкономика, использующая древесное сырье, включая отходы на всех стадиях производства и нанотехнологии, применяемые в производстве целлюлозы и других продуктов для промышленности (пищевой, кормовой, фармацевтической и химической). Объемы необходимого древесного сырья компании получают в основном на контрактной основе: 10\% из собственных лесов, 65\% из частных лесов, $10 \%$ из государственных, 15\% - от импорта за плату, состоящую из: платы за древесину на корню владельцам частных или государственных лесов; за заготовку древесины предпринимателям (лесосечные работы); за транспортировку древесины.

Воспроизводство лесных ресурсов осуществляют лесовладельцы за счет доходов от лесозаготовок. Однако, средства по уходу за молодняками могут поступать в виде государственных субсидий.

В стране преобладает интенсивная форма воспроизводства лесных ресурсов с искусственным лесовосстановлением с посадкой крупномерных саженцев со всеми видами обязательных уходов, внесением удобрений, проведенном прореживании и как, результат, сокращением периода рубки леса. Экстенсивная форма предполагает проведение лесовосстановления меньшим количеством посадочного материала на единице площади без последующих уходов, прореживаний и удобрений, что приводит к увеличению возраста рубки и снижению качества древостоя.

Работа лесного сектора Финляндии осуществляется на основе стратегической лесной политики, определяемой экономической организацией пользования и воспроизводства лесов, планированием, координированием действий в масштабах подразделений и всего кластера, а отдельные направления могут служить примером и быть использованы для повышения эффективности лесного сектора других стран [6].
Анализ экономической организации пользования и воспроизводства лесов в отдельных странах показывает, что при разных формах собственности на леса используется в соответствии с природно-производственными и экономическими условиями в основном контрактная система, способствующая улучшению взаимоотношений владельцев лесов с пользователями, повышению занятости населения, инновационному развитию лесного сектора. В России контрактную систему целесообразно и экономически выгодно применять при выполнении обязательств по лесному хозяйству. Сегодня известно, что в системе лесохозяйственных мероприятий остаются невыполненными охрана лесов от пожаров, защита от вредителей, болезней и лесонарушений.

Кроме того, лесопользователи не всегда технически и профессионально подготовлены к лесовосстановлению и уходу за лесными насаждениями. Наиболее качественно эти и другие работы могли бы выполнять, согласно договорам, специализированные лесохозяйственные государственные предприятия (учреждения), которые необходимо возрождать с привлечением малого и среднего бизнеса. При должной государственной поддержке такие лесохозяйственные предприятия способны выполнять любые лесные работы в малолесных и среднелесистых районах, в рекреационных лесах, в области защитного лесоразведения и оказывать необходимое содействие в лесохозяйственных делах лесопользователям.

В многолесных районах необходимо сохранить положительный опыт и совершенствовать арендные отношения в части заготовки древесины с совмещением контрактной системы в лесовозобновлении в особых случаях, разрешенных законодательством.

Владелец лесов должен периодически осуществлять контроль за выполнением своих требований через определенные промежутки времени (по примеру Канады - через каждые пять лет). Это повысит ответственность арендаторов за формирование лесных насаждений особенно в первые 10-20 лет в зависимости от способа лесовосстановления, за неистощительность использования лесов, эффективность развития лесного сектора и за будущее лесного фонда.

Основными направлениями совершенствования существующих форм организации лесопользования и воспроизводства лесов в современных условиях с учетом зарубежного опыта целесообразно считать:

- Введение закона о концессиях как формы организации лесопользования для повышения эффективности управления государственной собственностью с предварительной подготовкой нормативно-правовых актов; 
- увеличение срока аренды для возможности лесопользователям (арендаторам) осуществлять инвестирование в освоение лесов;

- Введение закона о воспроизводстве лесов с обязательствами лесопользователей о финансировании затрат;

- создание Центра по сохранению природных ресурсов (в том числе лесных);
- введение контрактной основы на выполнение работ в малолесных и среднелесистых районах по заготовке древесины и ведению лесного хозяйства;

- Введение государственного стимулирования за обеспечение качества воспроизводства лесов;

- усиление контроля государством лесопользования и воспроизводства лесов.

\section{ЛИТЕРАТУРА}

1. Лесной кодекс Российской Федерации по состоянию на 1 марта 2018 г. - М.: Проспект, 2018. - 128 с.

2. Отчет о результатах совместного экспертно-аналитического мероприятия «Анализ эффективности использования лесных ресурсов Российской Федерации в 2016-2018 годах» (совместно с контрольно-счетными органами субъектов Российской Федерации). [Электронный ресурс]. - режим доступа: https://ach.gov.ru/upload/iblock/f32/f32ecac2ceee85712845e5ec6b5914f7.pdf, свободный — Заглавие с экрана.— Яз.рус.

3. Декатов, Н.Е. Простейшие мероприятия по возобновлению леса при концентрированных рубках / Н.Е. Декатов. 一 Л.: Гослестехиздат, $1936 .-112$ с.

4. Гражданский кодекс Российской Федерации, часть 1 от 30.11.1994 г. № 51 - Ф3 (редакция от 28.06.2021 г.) с изменениями и дополнениями, вступившими в силу 08.07.2021 г.). [Электронный ресурс].— режим доступа: https://legalacts.ru/kodeks/GK-RF-chast-1/, свободный — Заглавие с экрана.— Яз.рус.

5. Комаров, И. Перспективы концессий в России.: 0бозреватель — Observer. — 2003.— № 6 (161). [Электронный ресурс] — режим доступа: httр:// militaryarticle.ru/obozrevatel/2003-obozrevatel/13329-perspektivy-koncessij-v-rossii, свободный - Заглавие с экрана. - Яз.рус.

6. Моисеев, Н.А. Экономика лесного хозяйства: учеб. пособие. - 2-е изд., испр. и доп./ Н.А. Моисеев — М.: ФГБОУ ВПО МГУЛ, 2012. - 399 с.

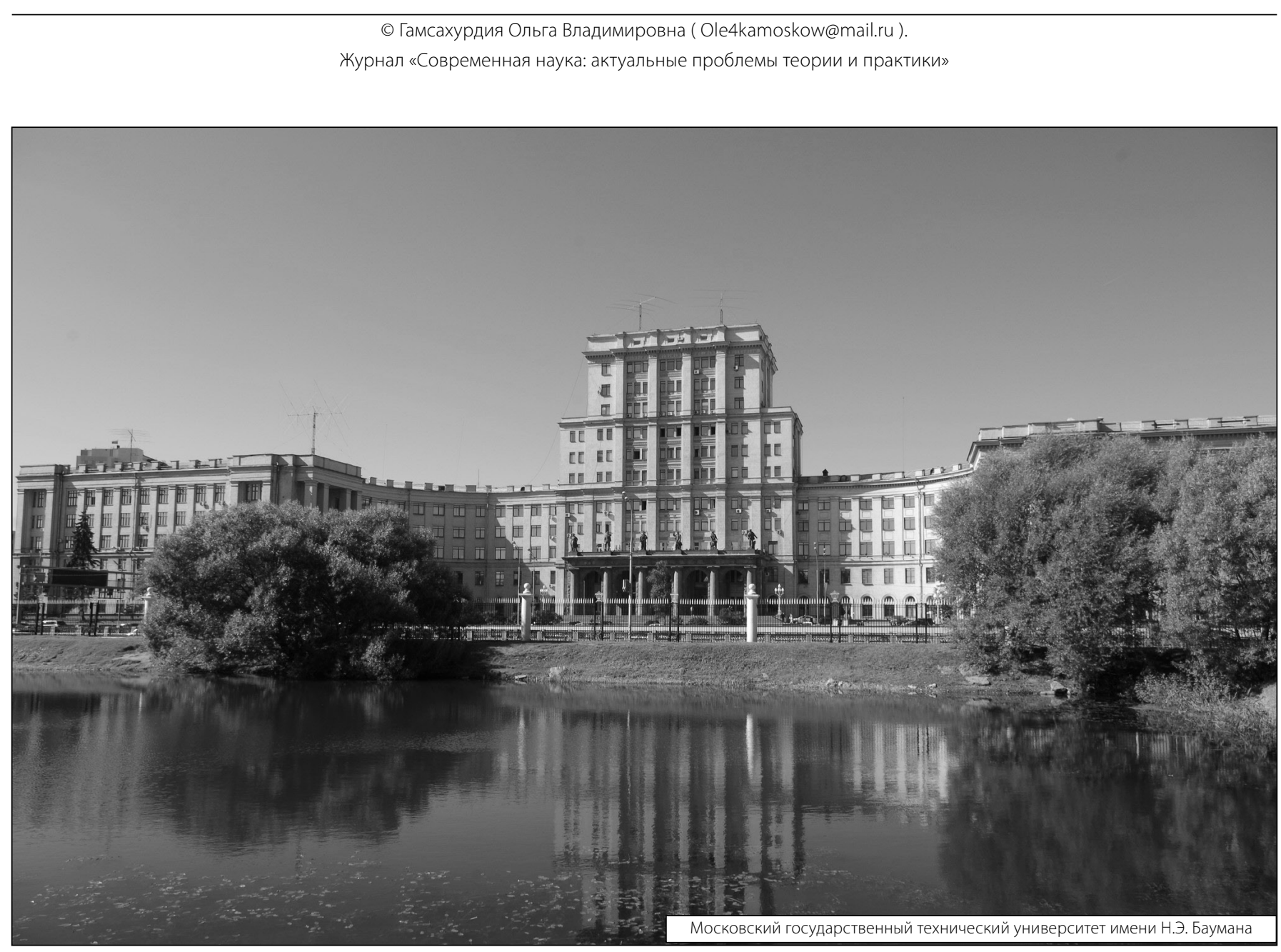

